\title{
THE USE OF NON - VERBAL COMMUNICATION IN THE TEACHING OF ENGLISH LANGUAGE
}

\section{BY}

\author{
OLADIPUPO ABDULLAHI. AKINOLA \\ DEPARTMENT OF GENERAL STUDIES \\ FEDERAL POLYTECHNIC EDE \\ OSUN STATE, NIGERIA. \\ oladipupo7@gmail.com \\ $+2348033895148$
}

\begin{abstract}
This paper attempted to investigate the use of various forms of non- verbal cues that are relevant to language teaching. It also examined its benefit to language education. Qualitative and quantitative research methods That is, survey research design and focus discussion group methods were adopted. The total number of 210 Copies of questionnaires was administered on the students while 23 different copies of questionnaires was also administered on the teachers apart from a ten - member focus group discussion organized to elicit information about their experiences in the use of non verbal communication. Findings showed that though the teachers were awarded of the benefit of non verbal communication to language teaching, they do not have access to those non-verbal instructional materials that are most essential. This is therefore having negative effect on the academic performance of the students. Finally, the paper offers some recommendations on the availability and how the knowledge of non-verbal communication will improve the academic achievements of English language learners as well as making the task of impacting knowledge an easy one for the teachers also.
\end{abstract}

Key words: Influence; Nonverbal Communication; Teaching; Language Education

\section{Council for Innovative Research}

Peer Review Research Publishing System

Journal: Journal of Advances in Linguistics

Vol. 4, No. 3

editorjalonline@gmail.com

www.cirjal.com 


\section{Introduction}

Communication is a wheel that keeps a human community going because it is through it that various people in the society can interact, inform, teach, persuade and entertain one another. Current Foreign Language Methodology maintains that language is communication (Allen, 1999) According to Canale and Merril (1980), communication is the exchange and negotiation of information between at least two individuals through the use of verbal and nonverbal symbols. Experts in non-verbal communication estimate that at least $65 \%$ of the meaning in any social situation is conveyed non-verbally (Burgoon, Buller and Woodall, 1989). Communication can generally be classified into verbal and non-verbal. Non-verbal, which is often referred to as 'wordless communication', 'communication without words', 'silent language', 'language within language', etc, is a significant aspect of the communication process and its use is mostly culturally determined (Aina, 2003). Verbal communication refers to all forms of communication that involves the use of words either in spoken or in written form.

Non-verbal communication refers to all forms of communication that do not involve the use of words. It is usually expressed in some other methods like using parts of the body attitudes or action rather than words (Asubiojo, Adewusi and Oyediran, 2005). It takes place intentionally and unintentionally.

Non-verbal communication is the oldest form of communication because it originated from the time of the early man.Frominfancy, when a child cannot express himself or herself verbally, non-verbal communication serves as important channelthrough which a baby passes information to his or her parents. Non-verbal communication also includes postures, glance,eye contact, vocal nuance, proximity, gestures, colours, signs, sounds, diagrams, paralanguage among others.

It is an important aspect of human communication because a lot can be communicated even without uttering a word. Moreover, it is used to reinforce and complement verbal messages because normal human interaction depends to some extent on non-verbal cues. The effectiveness of non verbal communication permits dialogues to take place within an assured framework. It is important to note that by nodding, smiling, eye-contact etc, both parties to a dialogue can determine whether to continue or stop the on- going discussion. Some of the major types of non verbal communication are highlighted below.

Kinesics: A situation when body movement communicates meaningfully with or without words. It is most essential when describing the size of an object or directing a stranger to find a particular location.

Le haptics: it entails the act of touching. It is most essential when a communicator intends to express affection, to calm or to interrupt depending upon the content.

Vocalic: it is the extra-linguistic aspect of communication that is concerned with the voice rather than the words of the speaker such that changes in a speaker's voice can be used to express different emotions or feelings.

Artifacts: This is an object language. It involves all intentional and unintentional display of material things such as implements, machines, art objects, architectural structures (as well as) the human body. For instance black colour indicates a bad omen or mourning mood while white connotes happiness. (Oladipupo, 2005).

Proxemics: This is a language of space which is also known as space or distance communication. Different kinds of distance can be kept by a speaker to communicate different specific messages.

Chronemics: Chronemics is the communication through the use of time. However what time communicates and individual attitude to time varies from one society to another.

\section{IMPORTANCE OF NON-VERBAL COMMUNICATION}

A large percentage of information is actually passed through non-verbal means of communication because most of the messages we receive or send are from non-verbal rather exact words we speak. Some other advantages of non- verbal communication are listed below:

1.Non-verbal communication serves as reinforcement to verbal communication.

2.It serves as a good substitute when communication breaks down.

3.It is usually simple and therefore easy to understand.

4.It is less expensive to use.

5.It can be used to regulate interaction, that is, non-verbal cues can be used to express when and when not to speak

6.It is multidimensional, that is unlike verbal communication which has only two modes (i.e. speaking and writing) nonverbal communicates with the use of pictures, dressing, colours, sounds, materials, actions, positions of the body, distance among others.

\section{THE USE OF NON-VERBAL COMMUNICATION IN THE TEACHING AND LEARNING OF ENGLISH LANGUAGE}

Education is the surest tool for the full emancipation and development of the individual as well as society they live. It is afact that education of any form cannot take place without communication. However, most people are of the opinion that education can only take through verbal communication alone. It is therefore necessary to note non-verbal communication. 
No teacher can impact knowledge without adopting non-verbal communication of different forms. Kellogg and Lawason (1993) maintain that $82 \%$ of all teachers' communications are non-verbal. Pennycook (1985) suggests that the constant interplay between verbal and non-verbal modes of communication must be considered in order to fully understand language acquisition. It is also pointed out that since non-verbal and verbal communication are complementary constituents of the whole process of interaction, knowledge of non-verbal can help students reach a fuller stage of foreign language communication (Kirch, 1979). The teaching of English Language which is a second language in Nigeria usually demands the non-verbal skills of both teachers and students. Infacts, many language teachers would agree that they rely more on non-verbal cues for effective teaching than teachers of other disciplines. Visual aids of all kinds are to the English Language learner what laying brick is to the apprentice bricklayer. It should also be noted that there is a wide area of teacher non-verbal activity which is directly related to the aims of language teaching. Some common types of non-verba0 communication that are relevant to teaching of English Language are discussed below:

\section{Body movement}

This refers to a situation when body movements are used to pass information. It can be broken into several components: facial expression, eye contact, gestures, and body postures. Movement of the face and body can give clues to a person's personality and emotionality state. Mere looking at a student can assist the teacher to know whether he/she understands what is being taught or not. This clue can also signal a wide range of learners' emotions such as fear, happiness, sadness, anger, surprise and interest. Facial expression of a learner can also serve as feedback to the teacher to know whether the learners are really following his discussion or not. Body posture can also convey a learner's attitude towards the interaction (e.g. relaxation, interest and boredon). Gestures and head movements are always used to show points of emphasis while hand movements can be used to add visual meaning to what has been said. For instance, one can use hand movements to discuss how big or small an object movements, parts of body movements.is. Therefore, synonym antonym and some other aspects of language can be clearly explained with the adoption of gestures, head

\section{Visuals}

These are visual presentations of information in simple, clear and logical manner for easy understanding and interpretation when knowledge is being impacted. It is usually presented through pictures, drawings, graphics, video clips, power point among others.

The visuals illustrations that are further explained in words can also be found in text books, journals, articles, posters in order to sustain the attention and to facilitate learning and understanding. In the course of teaching, a teacher can present pictures or drawings of a male and female, boy and girl, and, tall object and short object when explaining words and their opposites. It should be noted that pictures are old forms of communicating. It includes drawings and paintings of stones, walls, papers among others with the use of writing materials. Invention of camera has made it easy to produce and reproduce beautiful and exact pictures of the materials needed for learning.

\section{Statistical Presentations}

This consists of numbers and can be expressed in diagrams, charts, tables, figures, graphs, and plates. Table are collections of numerical data arranged in columns, and rows; figures refer to geometric diagrams, pictorial representations of textual matters e.g. charts and maps, while plates are photographs and other illustrations on glossy paper (Asubiojo,2006)

\section{Voice}

Voice deal with the extra-linguistic aspect of communication in language teaching, different voice pitches can be used to express different types of sentences. For instance, the following sentences can be differentiated through the use of different voice pitch or intonation.

(i) You have come.

(ii) You have come?

(iii) You have come!

Also, a person's tone while speaking reflects that he is angry, hostile, friendly, sober, excited and so on. Duration of pause also communicates. It could means that the person pausing is thinking of what to say or overwhelmed by effect of what the other has said.

It should be noted that the teacher's intonation and speech rhythm should be so moderated so that the message being passed will come out clearly, because a harsh voice which is too loud or a soft voice which is too low to be heard is not likely to carry the message home to the entire class.

\section{IMPORTANCE OF NON-VERBAL CUES TO THE EFFECTIVE LEARNING OF ENGLISH LANGUAGE}

Generally, people rely on non-verbal communication in order to encode and decode communicative messages. Nonverbal cues are used to mark units in which utterances are produced and also help the speaker activates and recall words, thoughts, images and ideas that become part of the utterances (Burgoon, Buller and Woodall, 1989) It is also possible for 
the utterances to be naturally segmented in to discernible units or phonemic clause by the voice qualities of pitch, rhythm, loudness, intonation, accentuation, syllabication, and the pause.

Combining body movements with instruction in the intonation of English facilitates learners' acquisition of the pitch and rhythm of the language. This auto synchronization helps learners know where to segment sentences into phonemic clauses, thus, enhancing language encoding. Ekman (1980) also identifies eight types of illustrators which perform different functions in nonverbal communication. These illustration are batons, underliners, ideographs, kinetographs, pictographs, rhythmic, spatial and deictic.

\section{Nonverbal Communication in Language Decoding}

Communications rely on nonverbal cues not only to encode but also to decode or comprehend messages. Nonverbal contribute to the understanding of messages in three ways; by heightening attention, by providing additional context and by facilitating recall. Apart from these, it also facilitates comprehension by activating concepts already stored as mental representations in the students memories (Allen, 1999) Allen and Vallen (1994) observe that gestures can be used to convey the meanings of specific words such as descriptive adjectives, prepositions of place, and action verbs.

\section{Nonverbal in Instruction Models}

Gestures play an important role in instructional models. The underlying concepts are that simple actions associated with language will facilitate retention. New vocabulary in the direct method can be presented by paraphrases, by miming the action or by manipulating objects. Hands gestures are also used to indicate where further work is needed and to elicit desired responses from the learners' in the classroom situation.

\section{Nonverbal as Teaching Strategies and in Classroom management}

There are various indications in which nonverbal cues are used as effective teaching strategies and in class management. In this regard, nonverbal are usually adopted to:

(i) Vary tempo

(ii) Control participation

(iii) Signal changes

(iv) Indicates who is to respond

(v) Cue choral response

(vi) Mark beginnings and ends of lessons

(vii) Give students an idea of what to expect (Allen 1999)

Barnett (1983) suggests that teachers develop a standard set of hand or arm gestures. For instance, some signals from the teacher may indicate when students should listen, repeat or speak loudly. Apart from these, nonverbal communication can also be used to promote dialogue. The teacher can point or establish eye-contact to pair students for group work, be silent to encourage reluctant students to participate and smile or nod to encourage and support students

\section{Methodology}

The population of the study is made up of both teachers of English language and senior secondary students of selected secondary schools in Osogbo 23 teachers were randomly selected from 10 selected secondary schools which include eight public and two private secondary schools. 210 students were selected from the 10 selected secondary schools it consists of 21 students from each of the 10 secondary schools selected. In other words, the total number of 233 respondents was selected in all.

The research instruments that were used were questionnaires and Focus Group Discussion in (FGD) Two different sets of questionnaire was administered to both the teacher respondents and student respondents. Apart from this, a focus group discussion was organized with a selected group of ten teachers in order to gain information about their views and experiences in the adoption of nonverbal communication in the classroom teaching situations. This focus group interviewing was particularly used for obtaining several perspectives about the topic in question.

\section{Summary if Findings}

From this study, the findings indicated that all the teachers of English language are aware of the use and relevance of nonverbal communication in the teaching of English Language as a second language though they do not use it in all necessary classroom situations in spite of the fact during their training as teachers, the importance of these instructional media were emphasized. They do not use it as a result of poor class arrangement, overcrowded class, inadequate training of financial problems and non-availability of suitable instructional media like power point, film, Television etc that are usually needed during teaching.

Averagely, the level of students exposure to the use of nonverbal communication during the teaching of English Language has significant influence on their academic performance. That is, to some extent, of nonverbal cues contributes positively to their academic performances in their various academic works. 
It is also discovered that most of the schools do not have modern facilities like video players, video clips, camera, projector, films, power point etc that are needed for academic purposes in this digital age. However, it is discovered that the only available nonverbal communication that are commonly used in all the schools include body movement, drawings, diagrams, charts tables, figures, graphs and plates. The availability of these "traditional" nonverbal instructional materials is probably due to the fact that it is less capital intensive. Thus, most teachers can individually afford it.

The findings also showed that the students who have access to most modern nonverbal instructional materials perform relatively better than those students that were not exposed to it because it is discovered that the students of a few private secondary schools who provide these facilities are performing relatively better academically.

The study also reveals that teachers use non-verbal communication during the teaching of English Language as a result of various benefits that both teachers and students derive from it. Some of these benefits are highlighted below:

- They allow for smooth flow of discussion.

- $\quad$ They take less room than when words are used for description and explanation

- They reveal easily and more clearly data that may not be easily seen in narrative form.

- Non-verbal cues like pointing, nodding, smiling, eye contact among others serve as complements to oral presentation.

- $\quad$ They make teaching interactional in nature because there is a good deal of evidence to suggest that normal human interaction depends to some extent on non-verbal cues.

They are used to demonstrate meaning: It is a fact that most language teachers rely a great deal on simple physical demonstration to drive home their points.

They help teachers to individualize instruction, evaluate success and diagnose the cause of learner's failure

The opportunity offered by video tape for editing, and for stopping for comment and discussion, and subsequent replay makes it the best medium to use in teaching and learning situation.

The use of nonverbal is inevitable;

i. When there seems to be breakdown communication between the teacher and the teacher and the student.

ii. When the topic is difficult to comprehend by the students.

iii. When words alone cannot clearly and adequately impact the intended ideas.

\section{CONCLUSION}

Though all these non-verbal cues are meant for improving teaching and learning, not all of them have been put in to efficient use to achieve expected results. Therefore, in order to achieve these, the following steps should be taken by the stakeholders in language education in order to improve the academic achievement of the learners, most especially English Language Learners:

1. The study of non-verbal communication, most especially, the aspects that are relevant to teaching and learning should be made compulsory for both the teachers and students at all levels of education

2. The use of audio visuals that are relevant to teaching and learning should be encouraged right from elementary through secondary education to the tertiary level.

3. Audio-visual materials like tape, projectors films, etc. need to be made less costly by reducing various taxes on its importation or production.

4. Seminars and conferences should be organized regularly to train and re-train the teachers on how to use nonverbal communication to achieve better result.

5. Teachers should also ensure that their enthusiasm, confidence and interest should come out clearly in the tones of their voices, stress pattern and intonation in order to effectively carry the students along.

6. Non-verbal communication such as drawing, chart and graphs should be presented as simple as possible. It must also be clear and neat for it to achieve maximum result.

7. For language teacher to use non-verbal communication to achieve maximum result, a great deal of language teaching must take place in smaller groups than at present.

8. Teacher should be made aware of their own nonverbal behaviour and learn to use that behavior more effectively In order to progressive improve academic performance of the learners'. 


\section{REFERENCES}

1. Aina, S. (2003) Anatomy of communication. Abeokuta. Julian publishers

2. Allen, D and valette, R.M (1994): Classroom Techniques: foreign Language and English as a second Language. Prospect Heights: wave land press.

3. Allan, L.Q. (1999); Function of Nonverbal Communication in Teaching and Learning a Foreign Language" French Review Vol.72 (3) 469-480

4. ASubiojo E.A, Adewusi C.O and Oyediran A.O (2005): Communication Theory and Practice.Ibadan. Aseda Publisting

5. Asubiojo E.A. (2006): Practical Guide to Research Writing. Ibadan. Aseda publishing

6. Babatunde, Folarin (1998): Issues in Applied Communication. Ibadan. Sterling Holden Publishers

7. Beernett, M.A. (2008): "Replacing Teacher Talk with Gestures: Nonverbal Communication in the FL Classroom" Foreign Language Annals vol 16 issues 3

8. Bert Decker (1999): How to Communicate Effectively. Britain Kogan Page limited.

9. Burgoom, J.K, David, B.B, Woodall, W.G.(1989):Non verbal Communication. http commfaculty.fullerton.edu/jhayes

10. Canale, M \& Meril,S (1980) "Theoretical Bases of Communicative Approaches to second Language Teaching and Testing" Applied Linguistics 1:1-47

11. Ebenedio, U.B and Anene-Eboyele, F.A.(2004): Language and Communication Skills. Ibadan Kraft Book

12. Ekman,P (1980): "Three Classes of Nonverbal Behavior” Aspects of Nonverbal Behaviour (Ed.) Walburga von Lisse: Sweats and Zetlinger.

13. Kellog, P and Lawason, B (1983): Envoy: Your Personal Guide to Classroom Management. Battle Ground: Michael Grinder.

14. Kirch, M,S (1979) "Nonverbal Communication Across Cultures": Modern Language Journal Vol, 63:416-423

15. Nicholas Beatie (1977): Non-Verbal Aspects of the Teaching and Learning of Foreign Languages". In Audio Visual Language Journal Vol. xv. No2.

16. Obilade E (1987): Verbal Communication. London. Omega Publisher.

17. Ogedengbe M.O,Akanbi C.T, OladepoK.T and Adewunmi I.K(1988):Technical Report Writing. Ibadan Macmillan

18. Oladipupo A.A. (2005) "Road Traffic Signs as Essential Means of Non-Verbal Communication Among Nigeria Road Users". In Journal of Business and Management (JOBAM) Vol.3

19. Pennycook, A (1985): "Action Speak Louder Than Words: Paralanguage Communication and Education" TESOL Quarterly Vol.19

20. Wylie. L (1985): Language Learning and Communication" French Review Vol.58:777-785 